\title{
Marine Geological and Geophysical Roots of the Ocean Observatories Initiative
}

\author{
Keir Becker \\ Rosenstiel School of Marine and Atmospheric Science, University of Miami - Miami, Florida USA
}

The ocean sciences are based on a rich exploratory heritage that dates back over a century, and expeditionary oceanography on dedicated research vessels will remain a vital component of current ocean sciences research-but a complementary new approach is also being embraced by the ocean sciences community. Recent decades have witnessed increasingly detailed spatial exploration of the oceans and seafloor, along with an evolution toward temporal exploration of change in the oceans and linkages among active processes through sustained time-series observations and adaptive long-term observatory technology. Understanding temporal evolution and linkages among processes in the oceans and the underlying plates will require a coordinated investment in a fulltime observational presence within the oceans and on and beneath the seafloor-an approach that is embodied in the budding Ocean Observatories Initiative (OOI) and Ocean Research Interactive Observatories Network (ORION) program within the National Science Foundation (NSF; Isern and Clark, in press; Clark, foreword to this volume).

While the value of sustained time series observations is acknowledged throughout all ocean sciences, some of the earliest coordinated efforts toward seafloor observatory science came from marine geology and geophysics, either within formal programs or from small groups of scientists. The purpose of this article is to provide a brief historical perspective of the marine geological and geophysical roots that have joined with comparable roots from other branches of ocean sciences (described in other articles in this issue) in the evolutionary process toward ocean and seafloor observatory science. The philosophical approach and investments in infrastructure for sustained time-series observations can be shared across all disciplines of ocean sciences, and ultimately, crossing the lines between disciplines may be one of the greatest benefits of the OOI.

\section{Seafloor Observatories for Geology and Geophysics}

Within marine geology and geophysics, the evolution toward a sustained time-series observational approach to understanding processes-as a complement to expeditionary investigations for spatial sampling and mapping - can be traced back at least two if not three decades. The evolution is documented in the reports of a number of international and national workshops that date back to the early 1980s, had an initial peak around 1994-1995, have continued fairly regularly since, and perhaps are enjoying a second peak at the current time as implementation plans are developed for the OOI. The rationale developed in workshops through the mid1990s led to a 1997-1999 "DEOS" (Dynamics of Earth and Ocean Systems) planning effort supported by NSF that culminated in an independent study on seafloor observatory science by the National Research Council (2000). Rather than summarize the workshop history, we focus below on the development of the scientific rationale within marine geology and geophysics for the OOI. The approach embodied in the OOI is implicit in discussions of scientific and technological needs for sustained time-series presence for at least two of the unified "New Directions" outlined in the "Futures" report of the 1996 FUMAGES workshop: "the societal imperative of making rapid progress in scientific understanding of complicated, non-linear systems" and "the appreciation that we must move beyond steady-state models to study geologic events as they happen." The scientific and infrastructural needs for sustained time-series observations are also highlighted in two subsequent NSF reports, the 2001 NSF "Decadal" report in Ocean Sciences ("Ocean Sciences at the New Millennium") and the 1999-2003 Facilities Plan for the NSF Geosciences Directorate.

\section{Two "Classes" of Seafloor/Ocean Observatories}

The geological and geophysical threads that coalesced in the 1997-1999 DEOS planning effort generally defined two "classes" of seafloor observatories:

- "Global" observatories, sited to complete the geometrically-even global coverage necessary to (a) image fully the interior of the Earth and understand whole Earth processes using irregular and unpredictable natural source signals such as earthquakes, as well as (b) to provide a synoptic view of oceanographic variables on a global spatial scale. With $70 \%$ of the Earth's surface 


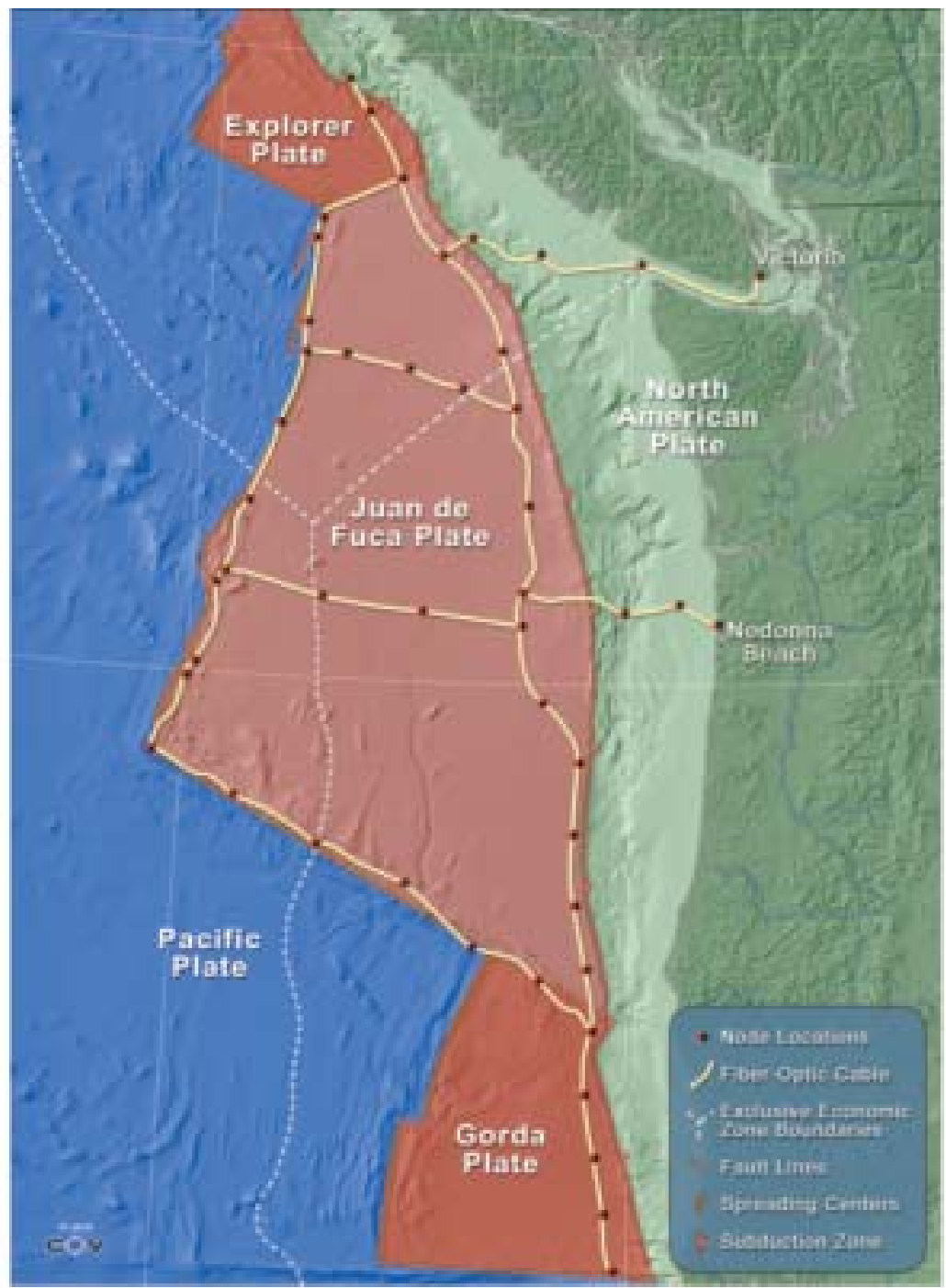

Figure 1. Notional design for cable runs and nodes for the NEPTUNE regional cabled observatory spanning the Juan de Fuca plate. Courtesy of NEPTUNE office at University of Washington (http://www.neptune. washington.edu).

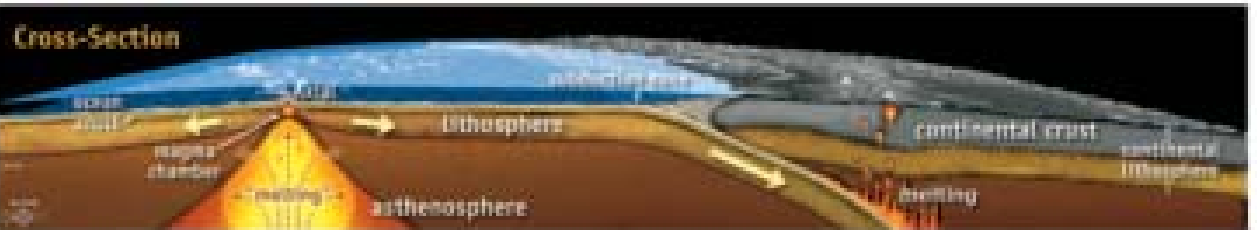

under the oceans, the global observing networks will never be complete without seafloor/ocean observatories

- "Active process" observatories more focused geographically where dynamic Earth systems are presently important near the surface or seafloor. Many examples are associated with active plate tectonic boundaries that occur predominantly beneath the seas: mid-ocean ridges, the settings of possibly the most complex interplay among tectonic, magmatic, hydrother- mal, and biological processes on Earth, and subduction zones, settings of tectonic and magmatic processes of great potential destructive impact on society. Other examples might be associated with strong oceanographic contrasts, such as processes associated with boundary currents that have important societal relevance in terms of weather and ocean productivity, or with the land-sea interface where complex processes shape the evolution of the coastline and coastal ecosystems with obvious societal relevance. 
These types of observatories are not fully distinct but represent two sides of a continuum of time and space activity scales of active Earth processes that can be fully understood only with sustained (over years) time-series observations from the oceans and underlying seafloor. A central tenet of the OOI is that the magnitude of the investment in infrastructure at any ocean observatory is going to require that all objectives, in a truly multi- and inter-disciplinary sense, be addressed at as many observatory sites as possible.

\section{Technological Approaches}

The 1997-1999 DEOS planning effort mentioned above focused on development of two principal technological approaches for seafloor geoscience observatories: cabled regional (plate-scale) observatories linked to shore by cable, and relocatable deep-water moored buoys linked to shore by satellite communications. These approaches have been pursued through feasibility studies funded by the National Oceanographic Partnership Program (NOPP) and NSF for (a) the NEPTUNE regional cabled observatory spanning the Juan de Fuca plate (NEPTUNE Phase 1 Partners, 2000; Figure 1) and (b) the DEOS Global Network of Moored-Buoy Observatories (DEOS Moored-Buoy Observatory Working Group, 2003; Figure 2). The OOI technological vision includes these two elements as well as a third focus on coastal active-process observatories (e.g., Schofield and Glenn, this volume). While it is not the purpose of this article to review the OOI technological objectives in any detail, it is relevant to briefly note here that it entails several key aspects:

- use of submarine cables (retired or specifically laid) for real-time power and two-way communication, for both coastal observatories and deep-ocean observatories,

- long-term deep-water moored-buoy systems with satellite communication where permanent cables are not available, feasible, or scientifically necessary,

- an expanded network of coastal observatories using all appropriate technologies,

- where appropriate, use of Deep Sea Drilling Program (DSDP)/Ocean Drilling Program (ODP)/International Ocean Drilling Program (IODP) boreholes for long-term subseafloor instrumentation,

- considerable need for use of University-National Oceanographic Laboratory System (UNOLS) ships and deep submergence assets for observatory work (in addition to ongoing use for expeditionary science), and

- desirability of international cooperation on utilization of all the above assets, as other nations develop initiatives comparable to the OOI (good examples being Japan and several European countries).

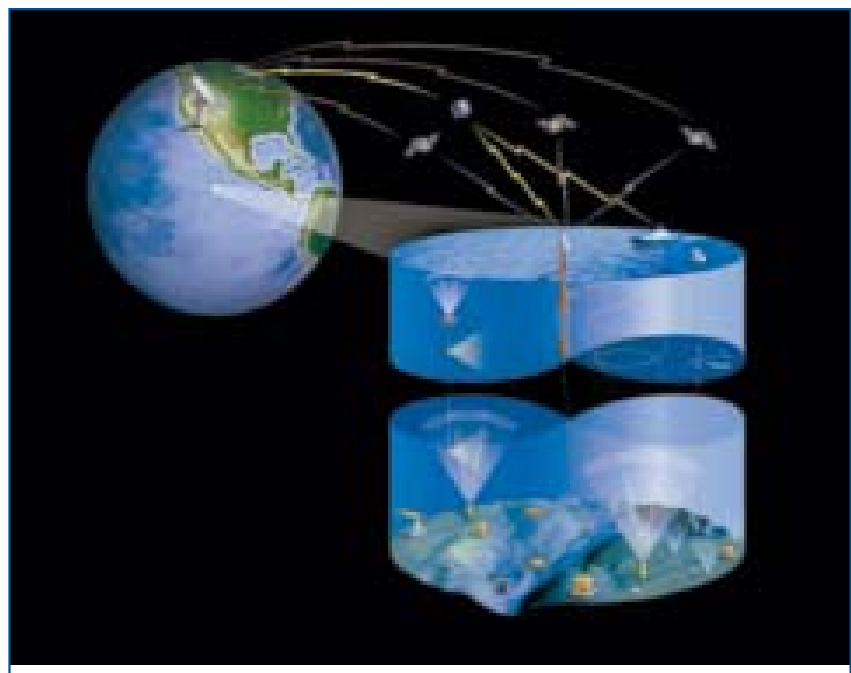

Figure 2. Notional diagram of a global mooring with a seafloor junction box to support power and telemetry to instruments in the seafloor and within the water column. Satellite telemetry is used to return real-time data to shore. Subsurface and surface moorings are supported for goals including air-sea flux measurements and acoustic thermometry. GPS satellites are used to locate the mooring to centimeter accuracy for seafloor geodesy. Figure courtesy of the Scripps Institution of Oceanography and Steve Cook, DecipherGraphics.

Other important philosophical tenets of OOI that originated not only in the DEOS planning effort but also from parallel planning efforts in the ocean sciences include:

- policies for open data access by scientists and public,

- a vision for providing scientific access to observatory infrastructure comparable to the UNOLS system that provides scientific access to ships and submersibles, and

- a strong emphasis on the educational and outreach opportunities for real-time data and communications from seafloor and ocean observatories.

\section{Geoscientific Opportunities and Motivation for OOI/ORION}

In this section we briefly highlight a few important fields in marine geosciences that will be greatly advanced through the capability for sustained timeseries observations and real-time communication to be provided by the OOI infrastructure. These cases are meant to be illustrative rather than exhaustive, and do not imply any special prioritization for the OOI/ORION. In virtually every case, the expeditionary heritage of spatial sampling and mapping has laid the groundwork essential to define critical hypotheses to be addressed with seafloor observatories. Hence, seafloor observatory geoscience is a natural expansion and complement to expeditionary geoscience in the oceans. 


\section{Global Earth Structure and Core and Mantle Dynamics}

From the beginnings of the plate tectonic revolution, mantle convection has been invoked to provide a fluid substrate for plate motion as well as the circulation and traction needed for a driving force, and to remove energy associated with radioactive decay within the Earth. Even today, however, mantle structure and the role and nature of mantle convection in plate tectonics are poorly understood in any detail and questions such as whether mantle convection occurs over the whole mantle or in two layers remain unsettled. Even less understood in detail is the nature of convection in Earth's core, its significance in plate tectonics, and specifics of its role in controlling the geomagnetic field.

Addressing these scientific problems requires geophysical tomographic imaging of whole Earth structure as well as very slow temporal changes in this structure. To do so with acceptable detail over the whole globe requires a geometrically even distribution of permanent observing station to utilize transient and unpredictable seismic, geomagnetic, and electromagnetic sources for the study of both structure and processes deep with Earth. At present, large gaps exist in the global networks of both seismic and geomagnetic stations, particularly in the eastern Pacific and southern oceans, which results in uneven sampling and limited tomographic resolution of deep Earth structure. The U. S. Ocean Seismic Network and international seismology communities have identified approximately 20 seafloor sites for long-term broadband seismic stations (ideally to be installed in boreholes drilled by DSDP/ODP/IODP) that would greatly improve the geophysical image of Earth's interior. Two basic types of scientific objectives have been highlighted in a 1995 Ocean Seismic Network (OSN) workshop report ("Broadband Seismology in the Oceans") as requiring such an ocean seismic network: "global problems requiring as broad a distribution of seismic stations as possible, including coverage in the oceans; and regional questions that address the seismicity, structure, and tectonics of specific features within the ocean basins. These two types of studies would require different types of instrumentation: i.e., globally-distributed permanent broadband stations and less permanent, redeployable instruments for regional studies, both of which are incorporated in the OOI technological strategy.

To date, ODP has drilled the half-dozen top-priority sites specified by OSN, and Japanese scientists have instrumented 3 such sites (in the NW Pacific) with broad-band seismometers (Suyehiro, 2002). Sites near the mid-Atlantic Ridge and Oahu have been instrumented for short-term instrumental tests, and a Japanese/French program is planned to instrument a site in the Indian Ocean. US scientists are involved in efforts to instrument two OSN borehole sites in the eastern Pacific. One of these is at the $\mathrm{H}_{2} \mathrm{O}$ cabled observatory (Chave et al., 2000), where seismometer installation is scheduled for summer of 2004; plans for instrumenting the other site are awaiting the implementation of the OOI moored-buoy capability.

The geophysical rationale for evenly distributed stations in the oceans complements the oceanographic rationale for Global Eulerian Observatories (GEO, see Gould, this volume). Many of the potential locations of these fixed components of a global ocean observing system are close to proposed OSN observatories, so the OOI infrastructure could serve both purposes. Some of the GEO stations that are not coincident with OSN global stations could be served with cabling and buoys constructed for the portable and plate-scale components of OOI

\section{Ridge-crest Processes}

Following the plate tectonic revolution, spreading centers became a natural focus of marine geological and geophysical investigations as the sites of active crustal accretion. Early efforts at spatial mapping and sampling led to the discovery of hydrothermal venting in the late 1970s, sparking a growing realization of the complexity of interlinked tectonic, magmatic, hydrothermal and unique biological processes at ridge crests. The RIDGE program evolved as a community effort to focus ridge-crest research and is notable for having incorporated an observatory component in its initial vision (Delaney et al., 1988). The RIDGE approach, which emphasized the importance of understanding the linkages among tectonic, magmatic, hydrothermal, and biological processes at actively spreading mid-ocean ridges, has been widely embraced internationally, and international ridge-crest scientists have made considerable progress using repeat expeditionary investigations at selected locations. Despite this progress, the specific nature of the linkages, their variations through time, cause-effect relationships, and potential relations to processes at transform and subduction plate boundaries and midplate processes remain poorly understood. Current expeditionary technology allows repeat visits and deployment of relatively low (battery-) powered instruments to make continuous measurements for periods of months to a year, but this is not sufficient to address the key questions about temporal variability and interlinkages among processes. For example, critical, transient hydrothermal and biogeochemical processes that occur at the time of an eruption have never been directly observed. By providing experimental nodes at selected segments along the global network of spreading centers, the OOI infrastructure would provide the power, control and bandwidth to enable interactive arrays of seafloor instruments capable of real-time observations of patterns and linkages in magmatic, heat and fluid output and the resultant biological responses. Geological and biological processes at ridge crests are often active at very short time scales, short enough for real-time video to be not 
only scientifically useful but also of great interest to the public. Thus the permanent observational presence with high-bandwidth link to the internet to be provided by the OOI will represent a very powerful educational and outreach opportunity.

\section{Subduction Processes, Crustal Deformation and Faulting}

As ocean crust ages, its evolution is controlled by a complex balance among tectonic processes, fluid flow and associated alteration, and off-axis volcanism. Ultimately, altered oceanic crust is returned to the mantle at subduction zones, which are marked by renewed volcanism, large earthquakes that have significant societal impact, and recycling of carbon and other chemical species by pore fluid expulsion. Documenting the history of the crust, the irregular episodicities in the processes that control its evolution and eventual subduction, and most important, the complex interlinkages among these processes, are of fundamental importance to understanding Earth dynamics. As with ridge-crest studies, these goals cannot be achieved by the traditional strategies of spatial mapping and occasional "snapshot" experiments, but instead require sustained, multiparameter time-series analyses enabled by seafloor observatories.

A prime example is the study of large earthquakes of great destructive power that occur at subduction zones, a key focus of the MARGINS and IODP SEIsmogenic Zone Experiments (SEIZE) initiatives. SEIZE seeks to understand processes associated with major earthquakes that originate on convergent plate boundaries at depths of tens of $\mathrm{km}$ or more, and to delineate linkages among plate motion, strain accumulation, fault evolution, and fluid flow along the plate boundary faults. The scientific strategy involves sustained time-series measurements at and below seafloor over the full earthquake cycle (tens of years or more) at selected representative subduction zones. This strategy requires an integrated, large scale seafloor observatory capability, of a scale and type that is similar to longterm experiments envisioned for on-land plate boundary studies (e.g., the SAFOD component of EarthScope). As with ridge-crest studies, the OOI infrastructure would enable the needed long-term observatory presence at a select few representative sites plus provide transportable arrays for moderate-term (order few years) comparative studies.

Subduction zones are the loci for the recycling of oceanic lithosphere and sediments that have accumulated on the seafloor since its initial formation at the ridge crest. The altered crust is subducted to depth, resorbed, and some portion is returned to the hydrosphere/atmosphere by volcanism. The sediments with entrained pore fluids and organic matter are either accreted or subducted at the plate margin. Accretion results in expulsion of hydrocarbon-bearing pore fluids and recycling of significant amounts of carbon to the ocean, dominantly as methane. The methane may be lost to the water column (and ultimately to the atmosphere) or it may be sequestered as gas hydrate or diagenetic carbonate deposits at the seafloor. Determination of the rates of carbon recycling and fixation at subduction zones is a first-order problem related to mass transfer of carbon at the seafloor, the oceanic/atmospheric carbon reservoirs, and perhaps to global climate. Because of the complex inter-dynamics of fluid flow, hydrate stability, carbonate kinetics, and microbial activity at convergent margins vary both temporally and a really, realistic estimates of global carbon flux will require long-term ( $2-5$ years) monitoring and active experimentation at borehole-based observatories in selected type examples at subduction margins.

\section{Subseafloor Hydrogeology and Biogeochemistry}

Hydrological processes at spreading centers and subduction zones are central to the chemical and thermal balance of the Earth and in plate boundary earthquake cycles. Ridge flanks and continental margins also host important hydrological flow regimes which are more difficult to detect but, when integrated over the area of the oceans, are at least as important for global fluxes between the oceanic crust and hydrosphere/atmosphere. In both passive and active continental margins, subsurface fluid flow systems are intimately related to processes associated with gas hydrate accumulation and periodic release. Sites of fluid venting-whether hot/warm in young crust or cold in subduction and passive margin settings-typically support unique life assemblages and ecosystems. Moreover recent evidence has shown that subsurface fluid flow regimes in all four of these characteristic seafloor environments may host extensive microbiological communities (the "subsurface biosphere") containing a large proportion of the world's biomass. Understanding the fluid flow processes, geochemical fluxes, and implications for subsurface microbiological communities requires more than occasional sampling at the seafloor. This is one of the integrating, cross-cutting themes for several major geoscience initiatives, including RIDGE, MARGINS, ODP and IODP, and is highlighted in the FUMAGES report. ODP has devoted considerable energy to this approach, having installed "CORK" borehole hydrogeological observatories since 1991 in 18 holes in several characteristic subseafloor hydrogeological regimes (Davis and Becker, 2001).

How can seafloor/subseafloor observatories specifically result in breakthrough advances in our understanding of subsurface hydrogeology and biogeochemistry? A 1998 workshop on hydrogeology of the ocean 
How can seafloor/subseafloor observatories specifically result in breakthrough advances in our understanding of subsurface hydrogeology and biogeochemistry? A 1998 workshop on hydrogeology of the ocean lithosphere (Davis and Elderfield, in press) concluded that the most fruitful approach would combine interdisciplinary spatial sampling with a sustained timeseries observational capability both on the seafloor and in ODP/IODP holes that penetrate the subseafloor in representative examples of each of the major characteristic geological environments. This is yet another example of the OOI philosophy that observatories alone will not result in scientific breakthroughs; rather, the combination of detailed contextual mapping plus carefully sited seafloor and subseafloor observatories in selected type locations will lead to the breakthroughs. Building on the recent experience with long-term hydrogeological instrumentation in ODP boreholes, future seafloor/ subseafloor hydrogeological observatories in representative sites could include the following long-term measurement capabilities: pressure, temperature, flow, chemical concentrations, seismicity, strain, in situ fluid sampling and microbiological culturing. Real time instrument control in such observatories would provide an important additional capability: the possibility to conduct perturbation experiments (e.g., tracer injection, thermal pulsing) to understand fluid flow processes and effects on subsurface microbiological communities. Where processes are especially active or episodic, as at ridge crests and possibly in gas hydrate systems on margins, an event response capability must be integrated within such observatory systems.

\section{Concluding Remarks}

When the NSF Ocean Observatories Initiative is implemented, it will provide the infrastructure that will enable a rich menu of oceanographic and geologi$\mathrm{cal} /$ geophysical research that requires a sustained time-series observational presence within the oceans and seafloor. The OOI will allow investigating not only the marine geological and geophysical themes summarized here, but also an equally compelling array of themes across all ocean sciences. Possibly more important, it will enable a truly interdisciplinary approach to studying Earth and ocean processes and provide a realtime observational presence that will engage the public and students of all ages in ocean studies. The history of oceanography can be described as one of pulses of discovery enabled by technological innovations. Thus, the innovative infrastructure to be provided by the OOI might also provide discoveries of ocean and Earth phenomena unforeseen even now. In addition to addressing scientific questions that are well-posed now, observations with the OOI infrastructure will almost certainly raise many new questions to challenge and engage both the public and the next generation of Earth and ocean scientists.

\section{Acknowledgements}

This article draws heavily on an "integration document" written in late 1999 by the steering committee members of the 1997-1999 DEOS planning effort supported by the National Science Foundation. The contributors included: A. Chave, J. Baross, B. Carson, J. Delaney, R. Detrick, T. Dixon, F. Duennebier, A. Dziewonski, C. Fisher, C. Nittrouer, J. Orcutt, and A. Schultz. That document was never formally published, but it was presented at a workshop conducted by the National Research Council in early 2000 as part of an NSF-funded study effort that led to the publication of the National Academy Press volume Illuminating the Hidden Planet.

\section{References}

Chave, A.D., F.K. Duennebier and R. Butler, 2000: Putting $\mathrm{H}_{2} \mathrm{O}$ in the ocean. Oceanus, 42(1), 6-9.

Davis, E.E. and K. Becker, 2001: Using ODP boreholes for studying sub-seafloor hydrogeology: results from the first decade of CORK observations. Geoscience Canada, 28(4), 171-178.

Davis, E.E. and Elderfield editors, 2004: Hydrogeology of the Oceanic Lithosphere. Cambridge University Press. Cambridge, UK, in press.

Delaney, J. et al., 1988: Scientific rationale for establishing long-term ocean bottom observatory/laboratory systems. In: The Mid-Oceanic Ridge-A Dynamic Global System, proceedings of a workshop. National Academy Press, Washington DC, 234-257.

DEOS Moored-Buoy Observatory Working Group, 2003: Implementation Plan for the DEOS Global Network of Moored-Buoy Observatories (prepared for the National Science Foundation). Scripps Institution of Oceanography, University of California, San Diego.

Isern A.R. and H.L. Clark, 2003: The Ocean Observatories Initiative: a continued presence for interactive ocean research. Marine Technology Society Journal, in press.

National Research Council, 2000: Illuminating the Hidden Planet: The Future of Seafloor Observatory Science. Washington, DC, National Academy Press, 135 pp.

NEPTUNE Phase 1 Partners, 2000: Real-time, long-term ocean and Earth studies at the scale of a tectonic plate: NEPUTNE Feasibility Study (prepared for the National Oceanographic Partnership Program). University of Washington, Seattle.

Purdy, G.M., conv, 1995: Broadband Seismology in the Oceans: towards a five-year plan, proceedings of an Ocean Seismic Network sponsored workshop held at Scripps Institution of Oceanography, La Jolla, CA, February 14-15, 1995. Joint Oceanographic Institutions, Inc., Washington, DC.

Suyehiro, K., 2002: Illuminating Earth's mantle and core: a new challenge for ODP. JOIDES Journal, 28(1), 55-60. 